\title{
From transcription to translation: new insights in the structure and function of Argonaute protein
}

\author{
Corinna Giorgi ${ }^{1}$, Carlo Cogoni ${ }^{2}$ \\ and Caterina Catalanotto ${ }^{2, *}$ \\ ${ }^{1}$ European Brain Research Institute 'Rita Levi-Montalcini', \\ Via del Fosso di Fiorano 64, I-00131 Rome, Italy \\ ${ }^{2}$ Department of Cellular Biotechnology and Haematology, \\ Sapienza University, Viale Regina Elena 324, I-00161 \\ Rome, Italy \\ * Corresponding author \\ e-mail: catala@bce.uniroma1.it
}

\begin{abstract}
Argonaute proteins play a central role in gene silencing pathways mediated by small RNA molecules. The ancestral function of small RNA-dependent silencing is related to genome protection against parasitic nucleic acids, such as transposons and viruses. However, new classes of small RNAs are continuously being uncovered in all higher eukaryotes in which they play important functions in processes ranging from embryonic development to differentiation to cell proliferation and metabolism. Small RNAs have variegated biogenesis pathways and accomplish distinct functions. Nevertheless, it appears that all small RNAs work merely as guides in recognizing the target RNAs invariably relying on the interaction with Argonaute proteins and associated factors for their biological function. Here, we discuss recent findings on the structure and regulation of mammalian Argonaute proteins and overview the various roles that these versatile proteins play in regulating gene expression.
\end{abstract}

Keywords: Argonaute; gene expression; GW182; miRNA.

\section{List of abbreviation}

miRNA, microRNA; RNP, ribonucleoprotein particle; RISC, RNA induced silencing complex; miRISC, RISC complex loaded by miRNA; pri-miRNA, primary-miRNA; pre-miRNA, precursormiRNA; RLC, RISC loading complex; siRNA, small interfering RNA; endo-siRNA, endogenous small interfering RNA; piRNA, Piwi-interacting RNA; Ago, Argonaute; PARP, poly(ADP-ribose) polymerase; PARG, poly(ADP-ribose)glycohydrolase; TGS, transcriptional gene silencing; H3K9me2, histone H3 lysine K9 dimethylated; H3K9me3, histone $\mathrm{H} 3$ lysine K9 trimethylated; Pol II, RNA Polymerase II; ncRNA, non coding RNA; eRNA, enhancer RNA; snRNA, small nuclear RNA; snoRNA, small nucleolar RNA; diRNA, double strand break induced RNA; rDNA, ribosomal DNA; TRBP, TAR-RNA binding protein.

\section{Introduction}

Argonaute proteins modulate gene expression at multiple levels, ranging from transcription to messenger RNA (mRNA) stability and translation. Their function is usually mediated by small non-coding RNAs (ncRNAs), which guide them via either extensive or partial base pairing to target RNAs (1). Binding to different classes of small RNAs and to different transacting factors activates different pathways of Argonautedependent gene expression regulation (2). Indeed, Argonaute protein family constitutes a class of highly specialised RNA binding proteins whose versatility is still not fully explored (3-5).

In mammals, microRNAs (miRNAs) represent the most abundant class of small RNAs characterised to date. They are functional in the form of a ribonucleoprotein particle, referred to as miRNA-induced silencing complex (miRISC), composed of a mature miRNA and an RISC of which Argonaute is the core component. miRNAs are 19-22 nucleotides (nts) in length and are transcribed by RNA polymerase II as primary miRNA transcripts harbouring $5^{\prime}$ cap and $3^{\prime}$ polyA tails $(6,7)$. In the nucleus, primary miRNAs are processed into precursor-miRNA hairpins of about 60-100 nts by the Microprocessor complex, including the RNase III enzyme Drosha and the protein DGCR8 (from the Di Giorge syndrome) (8-11). A small subgroup of miRNAs, called mirtrons, is instead encoded within introns of other genes and released on splicing from the intron-lariat (12). Regardless of the origin, a harpin precursor miRNA is produced in the nucleus and translocated to the cytoplasm via Exportin-5/ Ran-GTP $(13,14)$. Once exported, the precursor undergoes two processing steps required for the maturation of the RISC complex and is catalysed by the RISC loading complex, including the RNaseIII Dicer, TRBP and Argonaute (15-17). The Dicer cleaves the precursor, releasing a double-stranded RNA (dsRNA), referred to as the miRNA-duplex, harbouring $5^{\prime}$ phosphate $\left(5^{\prime}-\mathrm{P}\right)$ and $3^{\prime}$ hydroxyl $\left(3^{\prime}-\mathrm{OH}\right)$ ends and 2 -nt overhangs at the $3^{\prime}$ ends (18-20). The mature miRNA will result from unwinding of the duplex where the 'guide strand' is retained while the 'passenger strand' is removed. Selection of the correct RNA strand as 'guide' is carried out by TRBP on the basis of its thermodynamic properties. This step is critical, as a wrong selection would entail misregulation of off-target genes. TRBP then 'presents' the duplex to Argonaute, which will proceed to unwind and release the passenger strand while retaining the guide strand $(15,21,22)$. This final step results in the formation of the miRISC complex, which is competent for 
target mRNA recognition and regulation. Complementarity between miRNAs and their targets is not extensive; base paring between positions $2-7$ from the $5^{\prime}$ end of the miRNA, called the seed region, and the target mRNA is necessary and often sufficient to direct regulation (23).

Small ncRNAs may be also produced via Droshaindependent pathways (24-26). This is the case of endogenous small interfering RNAs (siRNAs), a class of endogenous siRNAs displaying extensive complementarity with their target RNAs. Endogenous siRNAs direct Argonaute slicing activity onto the target, resulting in its cleavage and degradation. These small RNAs are released via processing by Dicer of long dsRNAs deriving from transposons, intergenic regions or heterochromatic sequences whose products are long inverted repeats or convergent transcripts able to anneal with one another. Subsequently, the small RNAs are bound by Argonaute and proceed to silence their target genes (26-28).

Finally, a large class of small ncRNA molecules exists whose production is Dicer independent. Piwi-interacting RNAs (piRNAs) depend on a subclass of Argonaute proteins, the Piwi clade, for both their biogenesis and function. piRNAs are commonly transcribed from intergenic repetitive regions, and their processing depends on Piwi endonucleolytic activity in a complex amplifying scheme, referred to as the pingpong mechanism (29). Piwi/piRNA complexes are mostly restricted to the germline and are involved in silencing transposons, which in mammals are primarily long interspersed nuclear element or long terminal repeat retrotransposons (30-32). Silencing induced by piRNA/Piwi complexes occurs by directing the cleavage and degradation of target RNAs or by eliciting de novo DNA methylation and chromatin remodelling $(32,33)$. Interestingly, Piwi/piRNAs complexes have also been reported to target non-transposable elements in animals $(30,34-36)$, and recently neuronal piRNAs were described in Aplysia as epigenetic regulators of synaptic plasticity (37).

Mentioned above are only some in a multitude of pathways involving Argonaute proteins. These proteins display an impressive array of diversified functions and binding partners, mirrored by an ever-expanding literature. Here, we review the current understanding of Argonaute proteins' structure and function, focusing on, but not limiting our attention to, mammals.

\section{Argonaute evolution and structure}

The founding member of the Argonaute family of proteins, the Arabidopsis thaliana Ago1, was first identified in a genetic screen for genes involved in development (38). Mutations in the Ago1 gene led to developmental defects and a morphology resembling a squid known as 'Argonaute argo'. Few years later, Argonaute proteins were found to play a central role in RNA-mediated gene silencing, a phenomenon described in different eukaryotic organisms including fungi, plants and animals (39-41). Gene silencing mediated by small regulatory RNA molecules occurs ubiquitously in eukaryotes, playing a key role in defending eukaryotic genomes against viruses and genomic parasites such as transposons. Although the mechanistic details of the RNA-mediated gene silencing machinery may vary among different species, it appears that the general features and the central components of this regulatory pathway are universally conserved. Argonaute proteins are one of the few components that are always required for gene silencing, suggesting an ancestral function of these proteins in the genome defence systems.

Argonaute family members have evolved, by gene duplication and sequence divergence, to play crucial roles, not only in genome protection but also in a number of different biological processes ranging from development to differentiation to cell proliferation and metabolism (42). To date, Argonaute genes are widely present in eukaryotes and in some prokaryotic genomes. Typically, eukaryotic genomes contain one or more Argonaute genes: 1 gene is present in Schizosaccharomyces pombe, 5 paralogs are expressed in D. melanogaster, 10 in A. thaliana, 27 in Caenorhabditis elegans and 8 in human and mice (43). Based on phylogenic analyses, Argonaute proteins from plant, fungal and animal kingdoms can be subdivided into three clades: the Ago-like subfamily of proteins, defined depending on the similarity to A. thaliana Agol, present in animals, plants and yeast; the Piwi subfamily with members found only in animals and sharing similarities with D. melanogaster Piwi protein; and the C. elegans-specific Wago subfamily (44-47). Although the phylogenetic classification of Argonaute proteins in three clades is solely based on protein sequence similarity, it likely reflects a functional diversification of small RNA-based regulatory mechanisms in which they are involved (5).

Despite these functional differences, eukaryotic Argonaute proteins are generally characterised by four conserved regions (an N-terminal region, the PAZ domain, the MID domain and the PIWI domain) that are connected by two less characterised regions named L1 and L2 (for Linker1 and Linker2) (Figure 1). Argonaute-like genes were also found in prokaryotic genomes including both eubacteria and archaebacteria, and although they share sequence homology with eukaryotic Argonautes, the organisation of domains is variable and the PAZ domain is frequently absent $(48,49)$. During the past few years, full-length Argonaute proteins and isolated domains have been analysed by X-ray crystallography and NMR spectroscopy and functionally characterised by biochemical approaches, particularly in regard to their association with small RNAs.

The PAZ domain, composed of approximately 130 amino acids, is shared by both Argonaute and Dicer protein families. X-ray crystallography and NMR spectroscopy have revealed its three-dimensional structure, with a subdomain exhibiting an OB-like folding (oligonucleotide/oligosaccharide binding). This region is able to bind single-stranded nucleic acids, preferentially DNA in archeal and eubacterial Argonaute proteins, and RNA in their eukaryotic counterparts (50-52). Four aromatic residues within the PAZ domain are responsible for the interaction with the $3^{\prime}$ end of single-stranded RNAs or with $3^{\prime}$ overhangs of double-stranded small RNAs (53), without any sequence requirements (54-56).

Next to the PAZ domain, along the primary structure of Argonaute proteins, is the MID domain, exhibiting a 


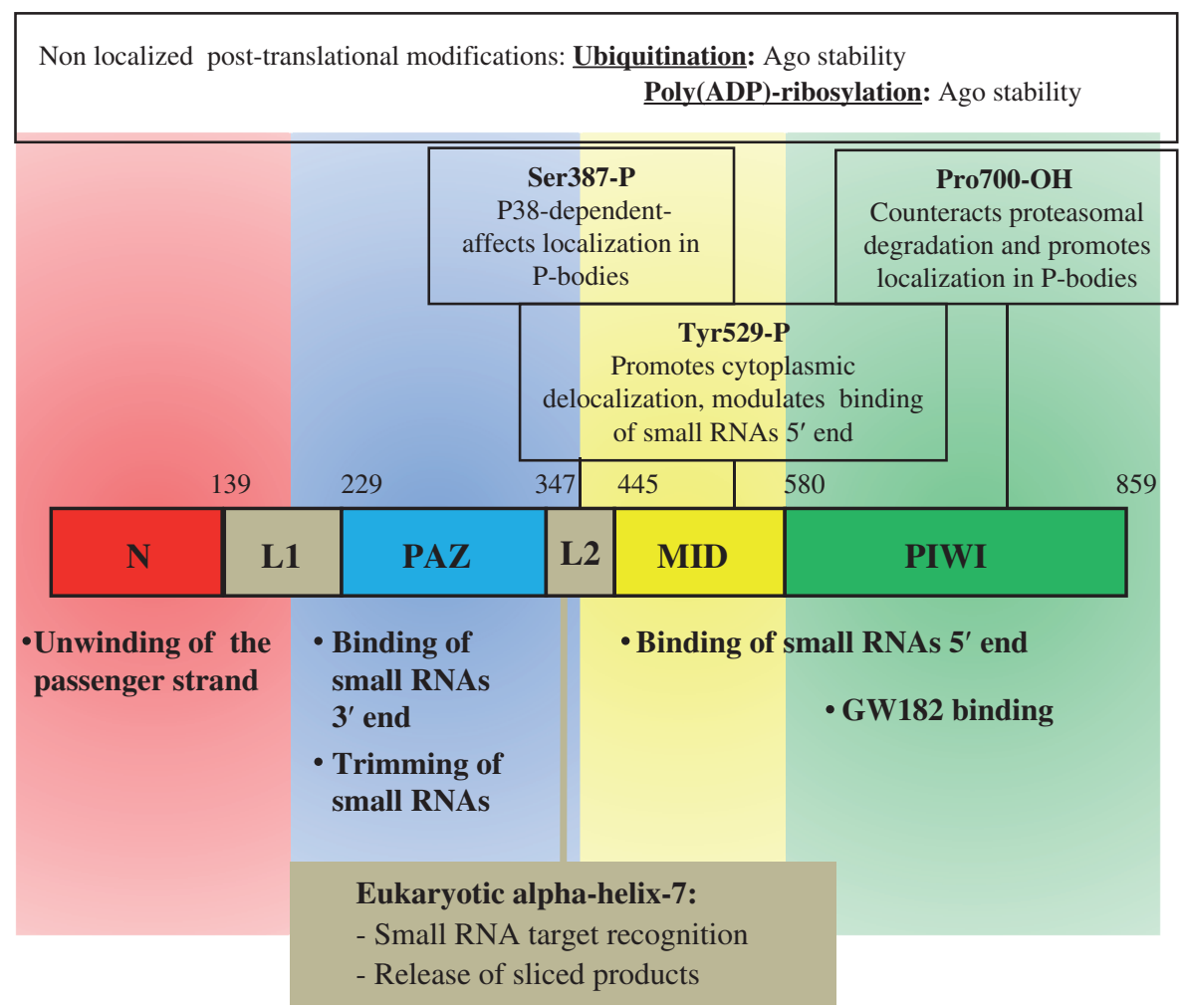

Figure 1 Schematic representation of Ago proteins.

Numbering is referring to Ago2 protein. Functions proposed for each individual domain are indicated at the bottom. Above are boxes showing the position, type and role of Ago post-translational modifications. (N) N-terminal domain; (L1-L2) Liker region1 and 2; PAZ, MID and PIWI domains.

Rossmann-like fold characteristic of the bacterial Lac1 repressor. This domain takes part in forming the binding site for the $5^{\prime}$ end of the guide strand of the small RNA (53, 57). Crystallographic studies of Argonaute proteins from archaeobacterial Archaeoglobus fulgidus and eubacterial Aquifex aeolicus revealed that the $5^{\prime}$ phosphate (5'-P) of the first nucleotide in the guide RNA is anchored by a divalent cation deeply within a highly conserved basic pocket formed by the PIWI and MID domains. This interaction excludes the $5^{\prime}$ terminal nucleotide from base pairing with the target mRNA $(58,59)$. More recently, Boland and co-workers resolved the structure of the MID domain alone and of the MID-PIWI portion of Neurospora crassa QDE-2, a eukaryotic Argonaute protein $(60,61)$. These studies show that the binding pocket for the $5^{\prime}$ end of the guide strand is highly conserved, positioned at the MID-PIWI hydrophilic interface. In addition, this interface is where nts 2-7 of the guide strand ('seed' region) are exposed so as to base pair with the target RNA (58-61). Moreover, the correct anchoring of the $5^{\prime}$ end of the guide is essential for placing the scissile phosphate of the target RNA adjacent to the Argonaute catalytic site responsible for its cleavage (62). In keeping with this, several computational and structural analyses suggest that the cleft between the MID and Piwi domains is key in determining preferential binding of Argonaute orthologs to a specific type of small RNA, based on their $5^{\prime}$ terminal nucleotide $(30,57,60,63)$.
The PIWI domain displays a ribonuclease H-like active site, which catalyses the cleavage of target nucleic acids (slicer activity) (64). RNaseH enzymes cleave RNA using DNA as a template, unlike eukaryotic Argonaute proteins, which prefer an RNA guide for their endonuclease activity. Regardless of the nature of the guide molecule, cleavage by these proteins generates a $3^{\prime}-\mathrm{OH}$ terminus and a $5^{\prime}-\mathrm{P}$ terminus. The active site of RNaseH enzymes contains an Asp-Asp-Glu/Asp motif and two divalent cations $(65,66)$, whereas Argonaute proteins exhibit a more degenerate catalytic centre (Asp-Asp-Glu/Asp/His/Lys) $(46,67,68)$. Mutagenesis of the conserved amino acid residues in the catalytic centre was shown to abolish target RNA slicer activity. Although the amino acid residues of the catalytic centre are generally well conserved among Ago proteins, not all Agos display endonucleolytic activity $(67,68)$. For instance, among the four closely related human Argonautes, only hAgo2 has a slicer activity, while hAgo1, hAgo3 and hAgo4 are not able to cleave target RNAs in biochemical assays $(67,68)$. Thus, it appears that conservation of the catalytic centre, although necessary, is not sufficient to ensure slicer activity.

The N-terminal domain was recently shown to direct small RNA duplex unwinding (69). This and prior observations contribute to depict a model for the formation of a competent RISC in which one of the two strands of the small RNA duplex is stably incorporated in the binding pocket of Ago protein. The first step consists of duplex loading onto Ago. A conformational change is required to allow for such a bulky molecule to be 
accommodated by Ago. To this end, ATP hydrolysis and the chaperone Hsp70/90 machinery induce a temporary distancing of the $\mathrm{N}$ domain from the body of the protein. Upon dsRNA loading, the $3^{\prime}$ end of the guide strand anchors itself to the PAZ domain. When the $\mathrm{N}$-terminus returns to its original position, it behaves as a wedge prying open the two strands and causing a partial unwinding of the duplex. In addition, $\mathrm{N}$-domain repositioning induces proper placement of the loaded dsRNA within the slicing Piwi domain. When siRNAs are loaded, the passenger strand is cleaved by Ago, a step required to reduce the duplex stability of the siRNA. This step is dispensable for miRNA duplexes whose stability is already weakened by mismatches. The final step consists of the passenger strand being removed, thus resulting in a mature miRISC complex.

Structural studies of prokaryotic Argonaute proteins revealed that their four domains are organised in two lobes, each containing two globular domains: the N-terminal and PAZ domains in one lobe and the MID and PIWI domains in the other. Recently, Schirle and MacRae (70) resolved the first crystal structure of a full-length eukaryotic Argonaute protein hAgo2. Their work confirms the general bi-lobed architecture of Argonaute proteins, with a central cleft for binding of guide and target RNAs, already observed in the prokaryotic homologues (53). Although the structure of isolated globular domains was quite similar between humans and prokaryotes, some differences in their relative positioning within the two lobes were present, likely influencing how the protein interacts with guide and target RNA molecules and highlighting specific functional features of eukaryotic Ago proteins. Firstly, hAgo2's structure revealed that its binding pocket, in which the guide molecule accommodates, is less hydrophobic than the one in prokaryotic Argonaute. Thus, bacterial Ago may not easily take in several $2^{\prime}$ hydroxyls present in RNA molecules, explaining the diverse preference for DNA vs. RNA guide of the prokaryotic Ago proteins. Secondly, the structural analysis of alfa-helix 7 within the L2 region, which is conserved in eukaryotic Argonautes but is not present in bacteria, revealed that this helix inserts a kink in the seed region of the guide RNA between nts 6 and 7. This structural modification interferes with the conformation needed by this sequence to interact with the target. Thus, target recognition requires a shift in helix 7 positioning, to allow target pairing to nts 6 and 7 of the guide. These data are consistent with previous observations on the importance of nucleotide 7 pairing in guide-target recognition in miRNA repression in mammals (23). Thirdly, two adjacent hydrophobic pockets were identified in the hAgo2 PIWI domain that are able to bind free tryptophan amino acids. It has been proposed that the two tryptophan-binding pockets may be the interaction sites for binding to GW motifs (glycine-tryptophan- rich regions) present in Argonaute-associated proteins, as GW182 is necessary to mediate specific Argonaute functions (see below).

\section{Expression of Argonaute genes}

The human genome encodes four Ago genes (AGO1-4) and four PIWI genes (HIWI, HILI, PIWIL3 and PIWIL4/HIWI2).
Human $A G O 1, A G O 3$ and $A G O 4$ are clustered in tandem on chromosome 1, whereas $A G O 2$ is located on chromosome 8. This distribution pattern is conserved in mammals, and a similar balance between AGO and PIWI encoding genes has been observed in Drosophila, displaying two AGO and three PIWI genes.

Ago proteins are expressed in most tissues, and their disregulation has been linked to several cancer disorders (71-74). Moreover, their relative abundance varies depending on the cell type, development and differentiation stage $(75,76)$, while PIWIs are primarily found in the germline $(30,77)$.

Recently, Valdmanis et al. (76) carried out an analysis on the regulated expression of $A G O$ genes, searching for elements in $A G O 3$ and $A G O 4$ coding regions that limit their expression. This analysis was prompted by the observation that $A G O 3$ and $A G O 4$ are expressed at low levels in mammalian tissues and the ectopic overexpression of their cDNAs is difficult to achieve experimentally compared with that of $A G O 1$ and $A G O 2$ (78). This suggests that some elements in their coding region may be curtailing protein expression. Indeed, the authors found that the N-terminal half of $A G O 3$ and $A G O 4$ coding regions contains uncharacterised elements that downregulate their expression post-transcriptionally. Interestingly, they also found that all Argonaute genes display a particularly high level of rare codon usage and that different expression levels may result from a diversified distribution of these codons along each gene. In addition, this distribution pattern is evolutionarily conserved; in $A G O 1$ and $A G O 2$, rare codons are concentrated in the first half of the gene, while $A G O 3$ and $A G O 4$ show an even distribution along their entire open reading frame. The enrichment in rare codons within the first 50 amino acids induces a uniform positioning of ribosomes across the beginning of the transcript, likely facilitating ribosome movement and translational efficiency (79); conversely, their extensive presence along a gene reduces protein yields in normal cells, while ensuring their expression under stress conditions. Preliminary results from mutational analyses of these codons seem to indicate that rare codons do participate in limiting the expression of $A G O 3$ and $A G O 4$. The conservation of this feature suggests that rare codon usage might be responsible for maintaining a dynamic balance between $A G O$ genes, ensuring a constant supply of miRNA effector proteins, Ago1 and Ago2, while allowing high levels of Ago3 and Ago4 expression only in specific cellular contexts.

As Argonaute proteins associate with miRNAs in a 1:1 ratio, their concentration in a cell is a limiting factor for miRNAs' function and is indicative of the magnitude of miRNAdependent regulation in that cell (80). All Ago proteins share the same binding potential with miRNAs, which are randomly sorted to the different Ago proteins based only on their relative concentration $(81,82)$. This apparent randomisation in Ago-miRNA binding does not rule out the possibility that association with a specific Ago protein may instruct miRNA function, as several recent studies suggest $(83,84)$.

Most mRNAs contain multiple miRNA binding sites in their $3^{\prime}$ untranslated regions (UTRs), which might be utilised at different times or in different cellular contexts. However, 
it is now clear that multiple miRNAs function cooperatively on a target $3^{\prime}$ UTR by stabilising Argonaute association with the mRNA. Broderick et al. (83) found that Ago proteins can exert different effects on the cooperativity of miRNAs. In HeLa cells and embryonic fibroblasts, miRNAs associated with Ago1, Ago3 and Ago4 always mediate silencing in a cooperative fashion, independently of the grade of pairing with the target. Instead, miRNAs bound to Ago2, and extensively paired with the target, elicit silencing in a non-cooperative manner. Thus, the relative abundance of Ago may be the discriminatory condition to obtain cooperation of adjacent miRNA binding sites on a given target.

Differences in Ago protein abundance may also affect $3^{\prime}$ end trimming of miRNAs. This, in turn, would affect their target mRNA specificity, as $3^{\prime}$ ends of miRNAs participate with the 'seed region' in target recognition. Juvvuna et al. (84) found that Ago2's PAZ domain binds less efficiently to the $3^{\prime}$ end of miRNAs compared with other Agos. As a result, miRNA 3' ends are shortened, likely because they are more accessible to trimming by exonucleases. The association of miRNAs with other Ago proteins would avoid this type of miRNA 'remodelling'. Interestingly, the authors found that many miRNAs undergo an extensive 3 '-terminal trimming during nervous system development. Indeed, this modification is accompanied by a decrease in Agol and a parallel increase in Ago2 levels. An intriguing model is that neuronal cells control their internal Ago1/Ago2 ratio, during differentiation, to adapt their miRNA pattern towards a new set of target transcripts (84).

\section{Argonaute proteins: new targets for traditional post-translational modifications}

Post-translational modifications of Argonaute proteins represent a hub for the integration of different signalling pathways and the coordination of cellular responses. Chemical modification of Argonautes can alter their cellular localisation, their affinity to small RNAs and protein partners and their overall abundance (Figure 1). The first post-transcriptional modification ascribed to hAgo 2 is hydroxylation at proline 700 by the prolyl-4-hydroxylase [C-P4H(I) (85)]. This modification stabilises Ago 2 by protecting it from proteasome-mediated degradation. In addition, prolyl-4-hydroxylation is required for Ago1 and Ago2 localisation to P-bodies, cytoplasmic foci where miRNAs accumulate and function, as well as sites of storage and degradation of translationally repressed mRNAs (86). In contrast, this type of chemical modification is dispensable for stress granule re-localisation of both Ago1 and Ago2 in response to cellular stress.

Phosphorylation of different residues of Ago proteins can also influence their P-body localisation. p38 MAPK kinase is responsible for serine 387 phosphorylation of Ago2, causing its concentration into P-bodies (87). The opposite effect is observed on the phosphorylation of Ago2-conserved tyrosine 529 , which promotes diffused cytoplasmic localisation and impairs its granular distribution (88). Interestingly, this modification acts as a molecular switch that turns off Ago2's affinity for small RNAs, thus significantly modulating its activity. Tyrosine 529 is positioned in the small RNA 5'-end binding pocket of the MID domain, where the addition of a negatively charged phosphate group may interfere with the binding of the negatively charged $5^{\prime}$ phosphate of the small RNA.

Subcellular localisation of Ago proteins, as well as miRNA silencing, is also regulated by polyADP-ribosylation (89). All mammalian Ago proteins are targets of both poly(ADP)-ribose polymerases and of their counterpart, poly(ADP-ribose) glycohydrolase. Interestingly, both poly(ADP)-ribose polymerase overexpression and poly(ADP) hydrolysing enzyme downregulation induce stress granule assembly and alleviate miRNA silencing. Conversely, stress conditions elicit strong poly(ADP)-ribosylation of Ago2 and again inhibition of miRNA-mediated silencing. Stress conditions may lead to an increase in poly(ADP)-ribose polymerases activity and/or a decrease in poly(ADP) hydrolysing enzyme activity. Either way, the end result is an increase in poly(ADP)-ribosylation of Ago and possibly a decrease in affinity for their target mRNAs or RISC-associated factors. This bulky modification may actually sterically interfere with RISC complex integrity. Alternatively, the negatively charged poly(ADP)-polymers might disrupt the electrostatic equilibrium of the silencing complex. As we describe later on, Argonaute has also been shown to induce chromatin modifications. As Poly(ADP)ribosylation is critical in the modulation of chromatin remodelling complexes (90), it might well be that both cytoplasmic and nuclear functions of Argonaute are controlled by this post-translational modification.

Lastly, Argonate is ubiquitinated by several E3 ubiquitin ligases and targeted to proteasomal degradation. In mouse embryonic stem cells, overexpression of the E3 ubiquitin ligase mLin41 reduces Ago2 levels and inhibits miRNA-dependent silencing, whereas downregulation has the opposite effect. Conversely, mLin41 is target of the let-7 miRNA, and this reciprocal regulation constitutes an elegant feed-forward circuit: let-7 reduces mLin41 expression, thereby enhancing Ago2/miRNAs-dependent gene silencing, while mLin41 attenuates miRNA silencing and reinforces its own expression (91).

\section{Argonautes in the nucleus}

In mammals, all four Ago proteins localise to both the cytoplasm and the nucleus (92). Initial evidence indicating a potential nuclear role of Argonautes was obtained by transfecting mammalian cell lines with exogenous siRNAs complementary to promoter sequences. This artificial targeting resulted in the silencing of the gene and, depending on the study, it required either Ago1 or Ago2 (93-97). Most reports on siRNAmediated transcriptional gene silencing (TGS) ascribe it to siRNA-induced epigenetic modifications of histones' lysines (H3K9me2 and H3K27me3), while ruling out CpG DNA methylation (94-96). However, Napoli et al. (97) found that siRNAs targeting promoter regions interfere with the assembly of the polymerase II pre-initiation complex, while observing no epigenetic effects. Lastly, another report indicates CpG DNA methylation as the silencing pathway involved 
in siRNA-mediated TGS (98). However contradictory, these studies have prompted further analyses to test whether artificially induced TGS is indicative of an endogenous pathway involving nuclear small RNAs. Supporting this idea are computational analyses and the miRNA-promoter interaction resource database, which have identified multiple endogenous miRNA target sites within promoter regions $(99,100)$. Indeed, several studies have now confirmed that miRNAs act at the nuclear level to silence the transcription of target genes, albeit via different proposed mechanisms (99, 101-104). The current model is that miRNAs are recruited onto target promoters by pairing to nascent non-coding RNA transcribed from the promoter region (Figure 2). This is indeed an experimentally proven model also in yeast (105). In mammals, miRNA-directed TGS depends on the formation of protein complexes that include Argonaute proteins, transcription factors and DNA and chromatin-modifying enzymes. Thus, miRNAs bound to nascent RNAs in the promoter region are thought to facilitate the binding of these inhibitory complexes onto the promoter.

As with exogenous siRNAs, it is unclear whether miRNAdirected transcriptional silencing depends primarily on histone modification, $\mathrm{CpG}$ methylation or interference with PolII assembly. There is controversy also on the role played by Ago1 and Ago2 in this silencing mechanism. In multiple studies, miRNA-mediated TGS is Agol dependent. Furthermore,
Ago1 is a good candidate as an effector protein in TGS as it interacts with Polycomb proteins such as the histone-lysine $N$-methyltransferase EZH2 (99, 102, 104, 106). However, Younger and Corey (103) recently characterised an Ago2dependent TGS mechanism in breast cancer cells. They found that the progesteron receptor gene promoter is silenced by four miRNAs, including miR-423-5p, which recognise a long ncRNA resulting from divergent transcription of the promoter region. They also showed that Ago2 is required for this miRNAdependent silencing, which is achieved by histone $\mathrm{H} 3$ methylation and reduced recruitment of RNA Pol II. Curiously, when analysing the degree of base pairing between miRNAs and their targeted promoters, it seems that miRNA-TGS requires Ago2 in the case of imperfect complementarity, while Ago1 is involved when base pairing is extensive $(99,102,103)$.

Induction of heterochromatic modifications by miRNAs has been recently described by Zardo et al. (104) as a key element in the terminal granulocytic commitment of myeloid progenitor cells. The authors have shown that this critical step is induced by miR-223, which induces TGS of the NFI-A transcription factor $(104,107)$. NFI-A promoter has a bivalent chromatin structure characterised by both euchromatic and heterochromatic histone modifications. Upon induction of granulocytic differentiation, miR-223 associates with Ago1, Dicer and Polycomb proteins and switches off NFI-A transcription

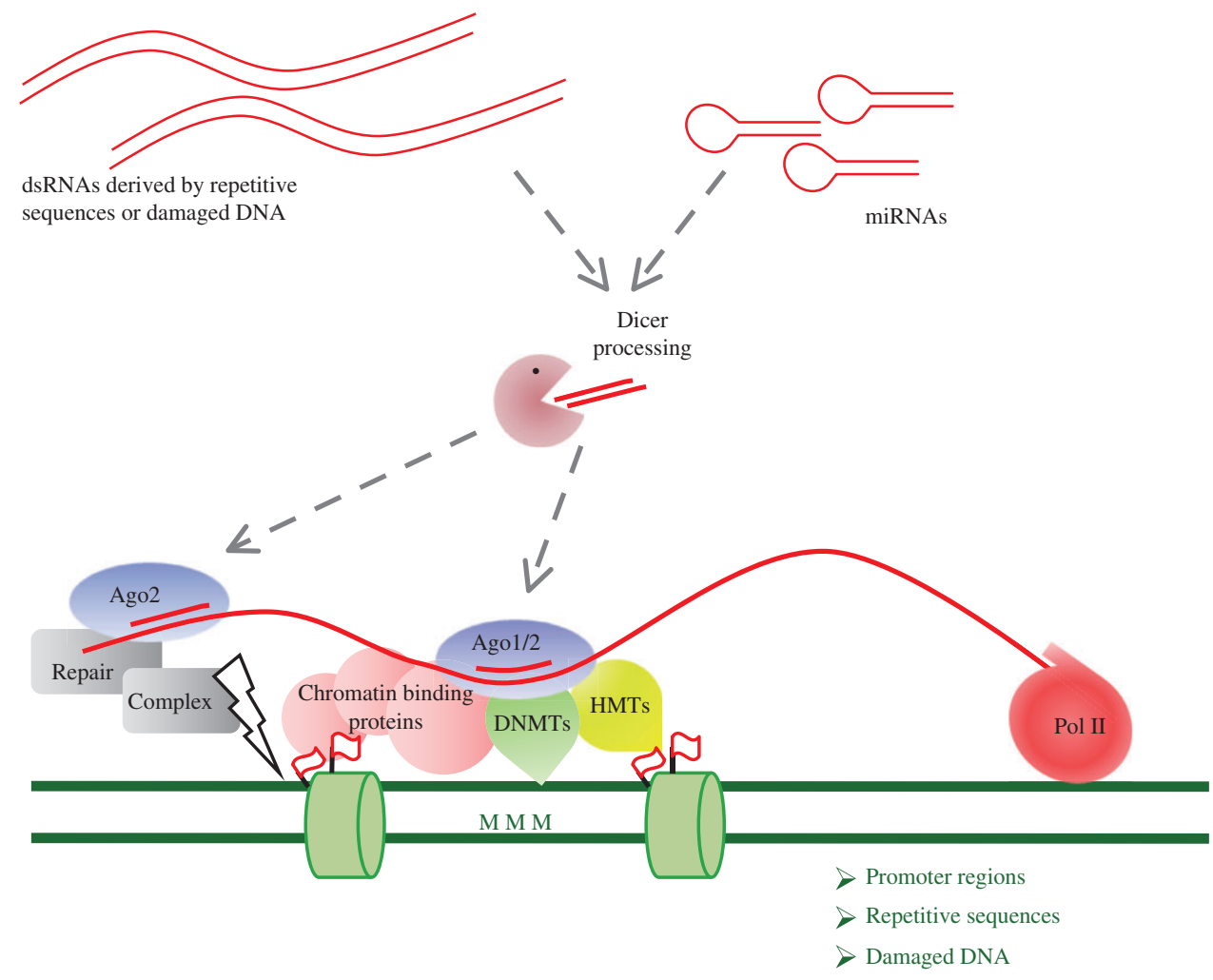

Figure 2 Proposed models of Ago roles in the nucleus.

Argonaute-bound small RNAs interfere with transcription by base pairing with nascent non-coding transcripts at the promoter level. Argonaute proteins recruit DNA methyltrasferases (DNMTs) and/or histone methyltransferases (HMTs), thus modifying the local heterochromatic state. In mammals, both Ago1 and Ago2 seem to be involved in chromatin remodelling. In a separate pathway, upon DNA damage, small RNAs are produced from the site. Ago2 bound to these small RNAs then recruits the DNA repair machinery to the damaged sequences. 
by inducing the heterochromatic state of the promoter, thus resolving its bivalent chromatin character. Confocal microscopy analyses carried out on mitotic cells suggest that miR223 directly interacts with native chromatin. This interaction occurs via two evolutionarily conserved sequences close to the NFI-A transcription start site, which are complementary to the seed region of miR-223. In another study, Argonaute and miRNAs were also shown to induce gene expression by recruiting RNA Pol II at targeted gene promoters (101).

Recent developments in genome-wide and transcriptome-wide sequencing approaches led to a major shift in our perception of gene regulation and small RNAs' functions. By adopting these techniques, a vast number of novel classes of small- and long ncRNAs have been unveiled, representing the majority of transcribed RNA species in the cell (3). Several of these ncRNAs are devoted to regulating transcription by targeting either promoter (promoterassociated small RNAs) or enhancer regions (eRNAs). While often their biogenesis seems to be the result of divergent or bi-directional RNA Pol II transcription, their mode of action and trans-acting factors are almost entirely unknown. Interestingly, a recent deep-sequencing analysis of mammalian Argonaute-associated small RNAs shows that Agos bind to many non-miRNA classes of RNAs, including nuclear-localised snRNAs and nucleolar snoRNAs. The authors also observed a significant enrichment in small RNAs overlapping promoter regions associated with Argonaute proteins. Thus, at least a fraction of the recently identified promoter-associated small RNAs may function through interaction with Ago proteins (108).

Argonaute's ability to recruit chromatin remodelling enzymes might also be involved in alternative splicing in human cells. Transfection of endogenous siRNAs complementary to sequences near an alternative exon was shown to affect alternative splicing of the mRNA. Two studies performed on this subject reached opposite conclusions on the involvement of Ago1 vs. Ago2 in this modulation (109, 110). The 'modus operandi' of Ago1 in controlling alternative splicing might be the same used in TGS; pairing between the siRNA and the nascent transcript mediates binding of chromatin-modifying complexes, thus inducing epigenetic modifications of the target gene. These modifications can lead to a reduction in the processivity of Pol II elongation (109), which, in turn, can result in a higher inclusion of alternative exons. Indeed, siRNAs induce exon inclusion when the transcription of a reporter is activated by $\mathrm{Sp} 1$, a transactivator that supports initiation, but not when VP16, promoting both initiation and elongation, is used. Differently, Ago2-mediated exon skipping seems to be independent from both heterochromatic modifications and the slicer activity of Ago2 (110).

Argonaute's roles within the nucleus might expand to include an involvement in DNA damage responses. In plants, preliminary data suggest that RNA molecules are transcribed from DNA at the damaged locus and converted into dsRNAs. These duplexes are then processed by Dicer to double-strand break-induced RNAs, which lead Ago2 and DNA repair proteins on the injured DNA (42) (Figure 2). This model finds support also in $N$. crassa, in which small RNAs originated by rDNA repetitive loci are associated with QDE-2 protein after DNA injuries (111). Moreover, knockdown of Dicer and Ago2 in HeLa cells reduced DNA repair, suggesting a not well defined yet conserved function of Argonaute and small RNAs in this process (42).

\section{Argonaute's roles in miRNA-induced repression}

The primary role of mammalian Argonaute is to induce silencing of miRNA-bound mRNAs, interfering with their translation and stability $(1,112)$. A large number of studies aimed at understanding the mechanism of miRNA-mediated repression have led to contradictory results, opening the debate on whether silencing of the target mRNA is achieved primarily via mRNA degradation or translational repression, and which step of translation is inhibited. Adding to the complexity of this issue, some miRNAs were also shown to activate rather than inhibit mRNA translation (113-115). Here, we briefly overview different proposed models of miRNA mode of action, focusing on roles played by Argonaute proteins and their interactors.

Initially, studies in $C$. elegans suggested that miRNA function is directed at inhibiting translation, leaving target mRNA stability generally unperturbed (116). Polysomal sedimentation analyses of lin-14 and lin-28 mRNAs revealed that while lin-4 inhibits their translation, they remain nonetheless associated with translating polysomes. This evidence suggested that the translation of miRNA targets is inhibited at a post-initiation step $(116,117)$. Other studies in mammalian cells also report the co-sedimentation of repressed mRNAs, as well as of Ago proteins and some miRNAs, with polysomal fractions, corroborating the idea that miRNAs act to block translation after initiation has occurred (118-122). It has been proposed that miRNAs block translation during elongation, either inducing ribosome dropoff (122) or eliciting degradation of nascent polypeptides (121). However, there is little experimental data to clarify the molecular mechanisms underlying the models proposed. A recent analysis of Ago's interacting proteins may suggest a potential explanation (123). Friend et al. (123) found that both nematode and mammalian Ago proteins form an inhibitory complex with Pumilio/FBF (PUF) and eEIF1A. Puf proteins modulate mRNA expression by recruiting the CCR4-NOT deadenylase, thereby reducing mRNA stability and repressing translation. eEIF1A is a GTPase essential for translational elongation, and its activity is inhibited by the formation of the ternary Ago-Puf-eEIF1A complex in vitro. In addition, Puf mutants that are unable to form this complex lose the ability to repress the translation of reporter mRNAs harbouring Puf-binding sites in their $3^{\prime}$ UTR. The authors also examined polysome profiles and ribosomal footprints, showing that translational inhibition by the ternary complex likely occurs after translation initiation, causing elongating ribosomes to stall at 100-140 nt downstream of the start codon. Interestingly, this site corresponds roughly to where the nascent polypeptide emerges from the ribosomal exit tunnel. Interaction with Puf proteins and the blockage 
of eEIF1A GTPase activity represents a novel and intriguing mechanism in which Ago proteins may interfere with translational elongation. However, there is yet no indication that this mechanism involves miRNAs or that miRNAs mediate translational repression via this pathway. Thus, the mechanistic details of a potential post-initiation model for miRNA-mediated translation repression remain unresolved.

Increasing experimental evidence suggests instead that miRISC complexes inhibit translation at an early step, interfering concomitantly with cap-dependent translation initiation and mRNA stabilisation. Contrary to the studies mentioned above, analyses of polysome profiles performed in C. elegans and in mammalian cells revealed that both endogenous and exogenous mRNAs targeted by miRNAs are not associated with polysomes; rather, they shift to lighter fractions containing few ribosomes or messenger ribonucleoprotein particles (124-127). Furthermore, several studies tested the involvement of cap-dependent translation initiation in miRNA-mediated silencing. Substituting the $\mathrm{m} 7 \mathrm{G}$ cap with the non-functional analogue ApppG cap at the 5' end of target mRNAs significantly relieves miRNA-mediated repression $(127,128)$. Consistently, mRNAs harbouring IRES that partially or completely bypass cap-dependent translation initiation are refractory to miRNA-mediated silencing (127-130). Interestingly, Walters et al. (131) found that susceptibility of IRES-containing mRNAs to miRNAs is rescued when both the m7G cap structure and the polyA tail are present. Altogether, these observations indicate that efficient inhibition by miRISC requires a functional cap structure and a polyA tail and that miRNAs likely act by interfering with eIF4E function. This interference could be achieved via direct interaction between miRISCs with the cap structure. While initially it was suggested that human Ago2 could interact with the cap via an eIF4E-like domain, this idea was then brought into question by two independent studies $(132,133)$. Yet again, an in vitro biochemical study found that Argonaute proteins involved in translational repression, like hAgo1-4, display potential capbinding activity albeit not via an eIF4E-like domain (57). However, a recent crystallographic and NMR analysis questions this finding, showing that hAgo2 does not bind significantly or specifically to cap analogues (134). Thus, a model of direct and competitive interaction of miRISC with the cap structure remains controversial.

Direct interaction between the cap-binding complex eiF4F and Ago proteins has also been proposed as a mechanism of interference with translation initiation. Increasing concentrations of purified eIF $4 \mathrm{~F}$ to an in vitro reconstituted translational system suppress miRNA-mediated silencing (128), suggesting that micro ribonucleoprotein particles may be able to interact and sequester cap-binding complexes. Moreover, Drosophila dAgo2 proteins were found to directly interact with eIF4E (135), possibly competing with eIF4G for binding. However, this interaction is not conserved, as mammalian Ago2 does not bind eIF4E (136). In addition, this hypothesis would be in contrast with the finding that in HeLa cells direct tethering of eIF4E or eIF4G to the $5^{\prime}$ UTR promotes translation of the downstream reporter mRNA regardless of let-7 binding in its $3^{\prime}$ UTR (127). Overall, while a plethora of data indicates that
miRISC interferes with cap-binding complex function, the underlying mechanism is still unresolved. Other studies have also proposed that miRNAs inhibit $80 \mathrm{~S}$ complex assembly, a step that occurs on scanning of the $5^{\prime}$ UTR and recognition of the first AUG codon (112).

An important aspect of miRNA-mediated repression of translation is the tightly coupled enhancement of target mRNA deadenylation and degradation. Indeed, while initial reports suggested that miRNAs elicit very little, if any, mRNA destabilisation $(116,137)$, it has become clear that target degradation is crucial to miRNA-mediated silencing (1).

High-throughput proteomic approaches were recently used to quantitatively compare changes in protein versus mRNA levels, on transfection or depletion of individual miRNAs $(138,139)$. Two studies found that miRNAs inhibit target gene expression only modestly and that mRNA degradation accounts for most of the regulation. Subsequently, Hendrickson et al. (140) developed a method based on DNA microarrays to assess mRNA abundance, ribosome occupancy and ribosome density of hundreds of genes targeted by human miR-124 in HEK-293T cells. This study also found a close correlation between the decrease in target mRNA levels and the translational rate, with mRNA destabilization accounting for approximately $75 \%$ of the change in protein synthesis.

Amongst numerous reports indicating the importance of mRNA degradation in the silencing cascade induced by miRNAs, a seminal study was carried out by the Bartel group, which adopted a recently developed ribosome profiling technique (141). This method is based on deep sequencing of ribosome-protected mRNA fragments, thus resolving the exact position and density of ribosomes on cellular mRNAs. The analysis was performed in HeLa cells transfected with miR-1 or miR-155 and in mouse neutrophils in which miR223 was knocked out. Similarly to Hendrickson et al., the results of this analysis indicate that in mammalian cells, miRNA-mediated silencing is predominantly (84\%) accounted for by mRNA destabilisation.

Once assessed that mRNA degradation plays a critical role in miRNA-mediated silencing, the debate has shifted to whether miRISC association simultaneously triggers mRNA deadenylation and translational repression, or whether one precedes the other. This debate is a hard one to solve as the two processes are tightly coupled in the cell and many factors involved in mRNA deadenylation also exert an inhibitory role in translation initiation. This coupling is due to the circularisation of the mRNA, mediated by the interaction between the PolyA binding protein (PABP) and eIF4G bound to the cap complex. This interaction is crucial to reinforce stability of the mRNA, to $40 \mathrm{~S}$ ribosomal subunit recruitment and to $80 \mathrm{~S}$ complex formation during translation initiation (112).

It has been observed that mRNAs targeted by miRNAs do not need to be translationally competent for deadenylation to occur, suggesting that this process is translation independent $(130,136,142)$. However, prior to deadenylation, the interaction between eIF4G and PABP needs to be disrupted in an in vitro assay (136), suggesting that translational inhibition may be nonetheless a prerequisite for deadenylation and subsequent mRNA decay. 
In keeping with this result are two important studies recently published in the same issue of Science. Bazzini et al. (143) replicated the ribosome profiling approach utilised by the Bartel group to monitor mRNA levels and ribosome occupancy of endogenous miR-430 mRNA targets in zebrafish during embryogenesis. Soon after fertilisation, zebrafish zygotes express miR-430 to elicit clearance of maternal mRNAs. By comparing ribosome profiles of wild-type and Dicer mutants, at stages that precede or follow miR-430 expression, the authors can finely and dynamically dissect in vivo when translational repression and mRNA decay begin to exert their effects. At $4 \mathrm{~h}$ post-fertilisation, just as miR430 appears, they observe an initial reduction in ribosome-protected fragments of maternal mRNAs without a corresponding decrease in mRNA levels, indicating that in this system translational repression precedes deadenylation. Indeed, at $4 \mathrm{~h}$ post-fertilisation, endogenous targets of mir430 are still polyadenylated. Interestingly, only $2 \mathrm{~h}$ later, the decreased levels in ribosome-protected fragments coincide with lowered mRNA levels, suggesting that subsequent to the onset of miRNA-mediated translational repression, mRNA decay becomes primarily responsible for silencing. In comparison, the ribosome profile analyses carried out by the Bartel group in mammalian cells were performed at $12 \mathrm{~h}$ post-transfection as the earliest time point, potentially failing to detect an early contribution of translational repression.

Consistent with translational repression occurring prior to deadenylation are the findings by Djuranovic et al. (144) in Drosophila S2 cells. They devised a luciferase-based reporter assay under inducible Metallothionein promoter to test the effects of both endogenous and exogenous miRNAs. Upon pulse induction by copper, the levels of protein output, total mRNA and polyadenylated mRNAs were monitored for both targeted and non-targeted constructs. In addition, the authors assay polyA length and the repression exerted by miRNAs on non-polyadenylated constructs. The verdict is clear: similarly to the conclusions drawn by Bazzini et al., miRNAs in Drosophila S2 cells act first by inhibiting translation, independently of deadenylation, and subsequently elicit deadenylation and decay. Moreover, the insertion of a natural elongation stall signal in the vicinity of the start codon allows them to determine that translation is inhibited during initiation or early elongation phases, as also observed by Bazzini et al. and the Bartel group.

It remains to be seen whether translational repression can occur independently of deadenylation in mammalian cells and whether miRNAs act by mechanisms that differ significantly depending on the $3^{\prime}$ UTR context. Other proteins bound to the 3' UTR and/or interacting with Ago proteins are in fact known to modulate miRISC's mode of action (112). Indeed, the complex array of RISC interactions with factors modulating mRNA stability and translation is starting to explain the molecular mechanisms underlying miRNA-mediated silencing.

A key mediator in the silencing pathway triggered by miRNAs in animal cells is the GW182/TNRC6 protein, recruited by Ago and acting downstream of it, as an effector of both mRNA decay and translational inhibition $(1,112,145)$. GW182/TNRC6 interacts with the AGO MID/PIWI domain via multiple glycine-tryptophan repeats ( $\mathrm{GW}$ repeats) in its $\mathrm{N}$-terminal region $(132,146,147)$. This interaction is essential to miRNAs' function, as overexpression of a peptide encompassing GW182 N-terminal domain competes with endogenous GW182 binding to AGO and inhibits miRNAmediated decay and tranlational repression of target mRNAs (132, 136, 147, 148). The C-terminal region of GW182 is considered the silencing domain as this domain alone is able to induce mRNA decay and translational inhibition of reporter constructs when tethered to their $3^{\prime}$ UTR $(149,150)$. This and other observations show that GW182, when tethered to mRNAs, can recapitulate miRISC repressive functions independently of AGO proteins, indicating that it is indispensable for miRNA function and that AGOs act by recruiting GW182 to the target mRNAs.

The question then becomes: how does GW182 elicit deadenylation and translational repression?

Mammalian and fly GW182 have been shown to bind directly to PABP through a PAM2 domain (PABP-interacting motif) located in their silencing domain $(65,136,151,152)$. Via this interaction, GW182 proteins have been proposed to induce the dissociation of PABP from the mRNA polyA tail, thus rendering it susceptible to deadenylases.

Recent studies, however, point in a different direction, one where deadenylases are directly recruited by GW182 to the target mRNA. At the end of 2011, three independent reports were published showing that human and Drosophila GW182 directly recruit CNOT1, a component of the cytoplasmic CCR4-NOT deadenylase complex, facilitating assembly of this complex onto targeted mRNAs (153-155). This interaction occurs via GW repeats (and other tryptophan-Gly/Ser/Thr repeats) dispersed both in the C- and N-terminal domains of GW182. Tethering of these GW motifs, even within a heterologous yeast protein, results in CCR4-NOT recruitment and silencing or the reporter mRNA (154). This and other tethering experiments presented in the three studies show that CCR4-NOT deadenylation complex is an effector of miRISC in repressing target mRNA expression, acting downstream not only of AGOs but also of GW182 (Figure 3). Interestingly, CCR4-NOT recruitment explains not only the mechanism underlying miRNA-mediated deadenylation but also the concomitant translational repression. Indeed, CCR4-NOT was able to repress the expression of reporters even when tethered to mRNAs lacking polyA tails (153-155). This observation is consistent with data recently obtained in Xenopous laevis showing that tethering of CCR4-NOT to mRNAs microinjected in the oocyte represses translation at the initiation step (156). Overall, in light of all the discrepancies and contradictory observations regarding whether translation or mRNA decay is primarily responsible for miRNA-mediated silencing, the role played by the CCR4-NOT complex in triggering both pathways might end up representing a fascinating and unifying solution.

\section{Concluding remarks}

Argonaute proteins translate small RNA binding to a target into action. Bound small RNAs guide Argonaute proteins 


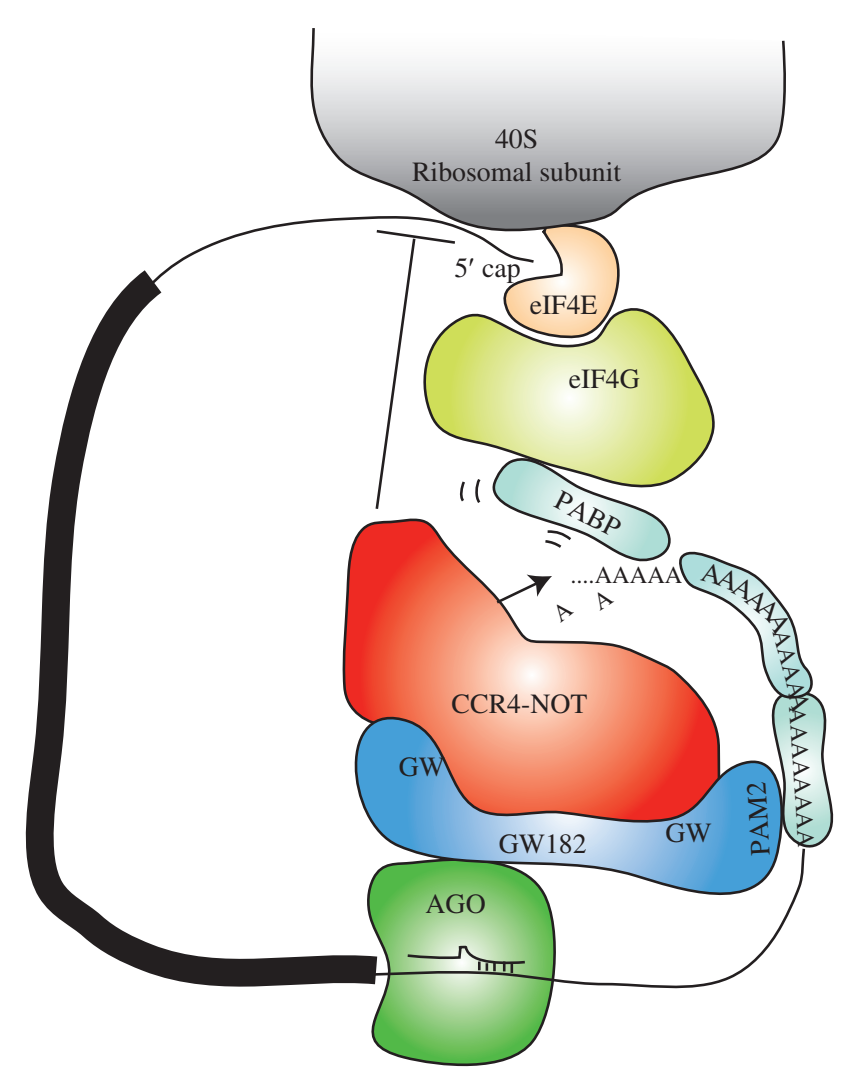

Figure 3 Model depicting GW182 recruitment of CCR4-NOT complex to target mRNAs.

The mRNA target is in a closed loop conformation, achieved via eIF4G-PABP interaction. Upon binding of a miRNA to the $3^{\prime}$ UTR of the target, GW182 bound to Ago recruits the CCR4-NOT deadenylase complex through interaction with its GW repeats. This complex in turn induces deadenylation of the transcript, which results in opening of the loop structure and accessibility to decapping enzymes and exonucleases. Concomitantly, CCR4-NOT triggers translational repression at the initiation step by an unknown mechanism and independently of its deadenylase activity (157). PABP, PolyA binding protein.

onto complementary sequences of target RNAs, regulating the expression levels of a wide variety of genes and in a complex array of different pathways. Argonaute ancestral role was to counteract the action of invading nucleic acids in order to defend genome integrity.

Subsequent duplication and divergence of Argonautes genes resulted in the development of new key functions for these proteins in diverse contexts such as cell cycle control, development and metabolism. Argonaute binding to a target can lead to different regulatory outcomes, ranging from modulation of transcriptional rates or mRNA splicing in the nucleus, to alteration of mRNA stability and translation efficiency in the cytoplasm. What elements turn Argonaute into proteins so versatile to influence such diverse pathways are still not fully understood. Their subcellular localization, post-translational modifications and binding partners are likely responsible of shaping their functions throughout the cell. Indeed, in the nucleus Argonaute proteins seem to exert their function on transcription and on splicing by recruiting chromatin remodeling enzymes onto target genes. On the other hand, in the cytoplasm, Argonaute proteins affect target mRNA stability and translation by interacting with GW182, which in turn recruits the CCR4-NOT deadenylase complex. Thus, compartmentalization and affinity to binding partners are crucial in determining the regulatory effects initiated by Argonaute-bound small RNAs on their target genes. Raising further the complexity of this fascinating cascade are Argonaute post-translation modifications which significantly affect their function by altering their subcellular localization, half life and affinity to small RNAs.

Another promising field that needs to be further explored, is the likely involvement of Argonaute in the expanding territory of non-coding RNAs, as these molecules appear to be a major regulatory tool of gene expression.

\section{References}

1. Huntzinger E, Izaurralde E. Gene silencing by microRNAs: contributions of translational repression and mRNA decay. Nat Rev Genet 2011; 12: 99-110.

2. Pasquinelli AE. MicroRNAs and their targets: recognition, regulation and an emerging reciprocal relationship. Nat Rev Genet 2012; 13: 271-82.

3. Aalto AP, Pasquinelli AE. Small non-coding RNAs mount a silent revolution in gene expression. Curr Opin Cell Biol 2012; 24: 333-40.

4. Ghildiyal M, Zamore PD. Small silencing RNAs: an expanding universe. Nat Rev Genet 2009; 10: 94-108.

5. Rother S, Meister G. Small RNAs derived from longer noncoding RNAs. Biochimie 2011; 93: 1905-15.

6. Cai X, Hagedorn CH, Cullen BR. Human microRNAs are processed from capped, polyadenylated transcripts that can also function as mRNAs. RNA 2004; 10: 1957-66.

7. Lee Y, Kim M, Han J, Yeom KH, Lee S, Baek SH, Kim VN. MicroRNA genes are transcribed by RNA polymerase II. EMBO J 2004; 23: 4051-60.

8. Denli AM, Tops BB, Plasterk RH, Ketting RF, Hannon GJ. Processing of primary microRNAs by the microprocessor complex. Nature 2004; 432: 231-5.

9. Gregory RI, Yan KP, Amuthan G, Chendrimada T, Doratotaj B, Cooch N, Shiekhattar R. The microprocessor complex mediates the genesis of microRNAs. Nature 2004; 432: 235-40.

10. Han J, Lee Y, Yeom KH, Kim YK, Jin H, Kim VN. The DroshaDGCR8 complex in primary microRNA processing. Genes Dev 2004; 18: 3016-27.

11. Lee Y, Ahn C, Han J, Choi H, Kim J, Yim J, Lee J, Provost P, Radmark O, Kim S, Kim VN. The nuclear RNAse III Drosha initiates microRNA processing. Nature 2003; 425: 415-9.

12. Westholm JO, Lai EC. Mirtrons: microRNA biogenesis via splicing. Biochimie 2011; 93: 1897-904.

13. Bohnsack MT, Czaplinski K, Gorlich D. Exportin 5 is a RanGTPdependent dsRNA-binding protein that mediates nuclear export of pre-miRNAs. RNA 2004; 10: 185-91.

14. Lund E, Guttinger S, Calado A, Dahlberg JE, Kutay U. Nuclear export of microRNA precursors. Science 2004; 303: 95-8.

15. Chendrimada TP, Gregory RI, Kumaraswamy E, Norman J, Cooch N, Nishikura K, Shiekhattar R. TRBP recruits the Dicer 
complex to Ago 2 for microRNA processing and gene silencing. Nature 2005; 436: 740-4.

16. MacRae IJ, Ma E, Zhou M, Robinson CV, Doudna JA. In vitro reconstitution of the human RISC-loading complex. Proc Natl Acad Sci USA 2008; 105: 512-7.

17. Maniataki E, Mourelatos Z. A human, ATP-independent, RISC assembly machine fueled by pre-miRNA. Genes Dev 2005; 19 : 2979-90.

18. Bernstein E, Caudy AA, Hammond SM, Hannon GJ. Role for a bidentate ribonuclease in the initiation step of RNA interference. Nature 2001; 409: 363-6.

19. Grishok A, Pasquinelli AE, Conte D, Li N, Parrish S, Ha I, Baillie DL, Fire A, Ruvkun G, Mello CC. Genes and mechanisms related to RNA interference regulate expression of the small temporal RNAs that control C. elegans developmental timing. Cell 2001; 106: 23-34.

20. Knight SW, Bass BL. A role for the RNAse III enzyme DCR-1 in RNA interference and germ line development in Caenorhabditis elegans. Science 2001; 293: 2269-71.

21. Haase AD, Jaskiewicz L, Zhang H, Laine S, Sack R, Gatignol A, Filipowicz W. TRBP, a regulator of cellular PKR and HIV-1 virus expression, interacts with Dicer and functions in RNA silencing. EMBO Rep 2005; 6: 961-7.

22. Lee Y, Hur I, Park SY, Kim YK, Suh MR, Kim VN. The role of PACT in the RNA silencing pathway. EMBO J 2006; 25: 522-32.

23. Bartel DP. MicroRNAs: target recognition and regulatory functions. Cell 2009; 136: 215-33.

24. Babiarz JE, Ruby JG, Wang Y, Bartel DP, Blelloch R. Mouse ES cells express endogenous shRNAs, siRNAs, and other Microprocessor-independent, Dicer-dependent small RNAs. Genes Dev 2008; 22: 2773-85.

25. Kim VN, Han J, Siomi MC. Biogenesis of small RNAs in animals. Nat Rev Mol Cell Biol 2009; 10: 126-39.

26. Watanabe T, Totoki Y, Toyoda A, Kaneda M, KuramochiMiyagawa S, Obata Y, Chiba H, Kohara Y, Kono T, Nakano T, Surani MA, Sakaki Y, Sasaki H. Endogenous siRNAs from naturally formed dsRNAs regulate transcripts in mouse oocytes. Nature 2008; 453: 539-43.

27. Tam OH, Aravin AA, Stein P, Girard A, Murchison EP, Cheloufi S, Hodges E, Anger M, Sachidanandam R, Schultz RM, Hannon GJ. Pseudogene-derived small interfering RNAs regulate gene expression in mouse oocytes. Nature 2008; 453: 534-8.

28. Yang N, Kazazian HH Jr. L1 retrotransposition is suppressed by endogenously encoded small interfering RNAs in human cultured cells. Nat Struct Mol Biol 2006; 13: 763-71.

29. Siomi MC, Sato K, Pezic D, Aravin AA. PIWI-interacting small RNAs: the vanguard of genome defence. Nat Rev Mol Cell Biol 2011; 12: 246-58.

30. Aravin AA, Hannon GJ, Brennecke J. The Piwi-piRNA pathway provides an adaptive defense in the transposon arms race. Science 2007; 318: 761-4.

31. Carmell MA, Girard A, van de Kant HJ, Bourc'his D, Bestor TH, de Rooij DG, Hannon GJ. MIWI2 is essential for spermatogenesis and repression of transposons in the mouse male germline. Dev Cell 2007; 12: 503-14.

32. Kuramochi-Miyagawa S, Watanabe T, Gotoh K, Totoki Y, Toyoda A, Ikawa M, Asada N, Kojima K, Yamaguchi Y, Ijiri TW, Hata K, Li E, Matsuda Y, Kimura T, Okabe M, Sakaki Y, Sasaki H, Nakano T. DNA methylation of retrotransposon genes is regulated by Piwi family members MILI and MIWI2 in murine fetal testes. Genes Dev 2008; 22: 908-17.

33. Brower-Toland B, Findley SD, Jiang L, Liu L, Yin H, Dus M, Zhou P, Elgin SC, Lin H. Drosophila PIWI associates with chromatin and interacts directly with HP1a. Genes Dev 2007; 21: 2300-11.

34. Lee EJ, Banerjee S, Zhou H, Jammalamadaka A, Arcila M, Manjunath BS, Kosik KS. Identification of piRNAs in the central nervous system. RNA 2011; 17: 1090-9.

35. Rouget C, Papin C, Boureux A, Meunier AC, Franco B, Robine N, Lai EC, Pelisson A, Simonelig M. Maternal mRNA deadenylation and decay by the piRNA pathway in the early Drosophila embryo. Nature 2010; 467: 1128-32.

36. Saito K, Inagaki S, Mituyama T, Kawamura Y, Ono Y, Sakota E, Kotani H, Asai K, Siomi H, Siomi MC. A regulatory circuit for piwi by the large Maf gene traffic jam in Drosophila. Nature 2009; 461: 1296-9.

37. Rajasethupathy P, Antonov I, Sheridan R, Frey S, Sander C, Tuschl T, Kandel ER. A role for neuronal piRNAs in the epigenetic control of memory-related synaptic plasticity. Cell 2012; 149: 693-707.

38. Bohmert K, Camus I, Bellini C, Bouchez D, Caboche M, Benning C. Ago1 defines a novel locus of arabidopsis controlling leaf development. EMBO J 1998; 17: 170-80.

39. Catalanotto C, Azzalin G, Macino G, Cogoni C. Gene silencing in worms and fungi. Nature 2000; 404: 245.

40. Fagard M, Boutet S, Morel JB, Bellini C, Vaucheret H. AGO1, QDE-2, and RDE-1 are related proteins required for post-transcriptional gene silencing in plants, quelling in fungi, and RNA interference in animals. Proc Natl Acad Sci USA 2000; 97: 11650-4.

41. Tabara H, Sarkissian M, Kelly WG, Fleenor J, Grishok A, Timmons L, Fire A, Mello CC. The RDE-1 gene, RNA interference, and transposon silencing in C. elegans. Cell 1999; 99: 123-32.

42. Wei W, Ba Z, Gao M, Wu Y, Ma Y, Amiard S, White CI, Rendtlew Danielsen JM, Yang YG, Qi Y. A role for small RNAs in DNA double-strand break repair. Cell 2012; 149: 101-12.

43. Hock J, Meister G. The Argonaute protein family. Genome Biol 2008; 9: 210.

44. Czech B, Hannon GJ. Small RNA sorting: matchmaking for Argonautes. Nat Rev Genet 2011; 12: 19-31.

45. Hutvagner G, Simard MJ. Argonaute proteins: key players in RNA silencing. Nat Rev Mol Cell Biol 2008; 9: 22-32.

46. Tolia NH, Joshua-Tor L. Slicer and the argonautes. Nat Chem Biol 2007; 3: 36-43.

47. Yigit E, Batista PJ, Bei Y, Pang KM, Chen CC, Tolia NH, Joshua-Tor L, Mitani S, Simard MJ, Mello CC. Analysis of the C. elegans Argonaute family reveals that distinct Argonautes act sequentially during RNAi. Cell 2006; 127: 747-57.

48. Karginov FV, Hannon GJ. The CRISPR system: small RNAguided defense in bacteria and archaea. Mol Cell 2010; 37: 7-19.

49. Makarova KS, Wolf YI, van der Oost J, Koonin EV. Prokaryotic homologs of argonaute proteins are predicted to function as key components of a novel system of defense against mobile genetic elements. Biol Direct 2009; 4: 29.

50. Lingel A, Simon B, Izaurralde E, Sattler M. Nucleic acid 3'-end recognition by the argonaute2 PAZ domain. Nat Struct Mol Biol 2004; 11: 576-7.

51. Lingel A, Simon B, Izaurralde E, Sattler M. NMR assignment of the Drosophila Argonaute2 PAZ domain. J Biomol NMR 2004; 29: 421-2.

52. Ma JB, Ye K, Patel DJ. Structural basis for overhang-specific small interfering RNA recognition by the PAZ domain. Nature 2004; 429: 318-22.

53. Song JJ, Smith SK, Hannon GJ, Joshua-Tor L. Crystal structure of Argonaute and its implications for RISC slicer activity. Science 2004; 305: 1434-7. 
54. Lingel A, Simon B, Izaurralde E, Sattler M. Structure and nucleic-acid binding of the Drosophila Argonaute 2 PAZ domain. Nature 2003; 426: 465-9.

55. Song JJ, Liu J, Tolia NH, Schneiderman J, Smith SK, Martienssen RA, Hannon GJ, Joshua-Tor L. The crystal structure of the Argonaute2 PAZ domain reveals an RNA binding motif in RNAi effector complexes. Nat Struct Biol 2003; 10: 1026-32.

56. Yan KS, Yan S, Farooq A, Han A, Zeng L, Zhou MM. Structure and conserved RNA binding of the PAZ domain. Nature 2003; 426: 468-74.

57. Djuranovic S, Zinchenko MK, Hur JK, Nahvi A, Brunelle JL, Rogers EJ, Green R. Allosteric regulation of Argonaute proteins by miRNAs. Nat Struct Mol Biol 2010; 17: 144-50.

58. Ma JB, Yuan YR, Meister G, Pei Y, Tuschl T, Patel DJ. Structural basis for $5^{\prime}$-end-specific recognition of guide RNA by the A. fulgidus Piwi protein. Nature 2005; 434: 666-70.

59. Parker JS, Roe SM, Barford D. Structural insights into mRNA recognition from a PIWI domain-siRNA guide complex. Nature 2005; 434: 663-6.

60. Boland A, Huntzinger E, Schmidt S, Izaurralde E, Weichenrieder O. Crystal structure of the MID-PIWI lobe of a eukaryotic Argonaute protein. Proc Natl Acad Sci USA 2011; 108 : 10466-71.

61. Boland A, Tritschler F, Heimstadt S, Izaurralde E, Weichenrieder O. Crystal structure and ligand binding of the MID domain of a eukaryotic Argonaute protein. EMBO Rep 2010; 11: $522-7$.

62. Elbashir SM, Martinez J, Patkaniowska A, Lendeckel W, Tuschl T. Functional anatomy of siRNAs for mediating efficient RNAi in Drosophila melanogaster embryo lysate. EMBO J 2001; 20: 6877-88.

63. Frank F, Sonenberg N, Nagar B. Structural basis for 5'-nucleotide base-specific recognition of guide RNA by human AGO2. Nature 2010; 465: 818-22.

64. Nowotny M. Retroviral integrase superfamily: the structural perspective. EMBO Rep 2009; 10: 144-51.

65. Jinek M, Doudna JA. A three-dimensional view of the molecular machinery of RNA interference. Nature 2009; 457: 405-12.

66. Nowotny M, Gaidamakov SA, Crouch RJ, Yang W. Crystal structures of RNase $\mathrm{H}$ bound to an RNA/DNA hybrid: substrate specificity and metal-dependent catalysis. Cell 2005; 121: 1005-16.

67. Liu J, Carmell MA, Rivas FV, Marsden CG, Thomson JM, Song JJ, Hammond SM, Joshua-Tor L, Hannon GJ. Argonaute2 is the catalytic engine of mammalian RNAi. Science 2004; 305 : 1437-41.

68. Meister G, Landthaler M, Patkaniowska A, Dorsett Y, Teng G, Tuschl T. Human Argonaute2 mediates RNA cleavage targeted by miRNAs and siRNAs. Mol Cell 2004; 15: 185-97.

69. Kwak PB, Tomari Y. The N domain of Argonaute drives duplex unwinding during RISC assembly. Nat Struct Mol Biol 2012; 19 : $145-51$.

70. Schirle NT, MacRae IJ. The crystal structure of human Argonaute2. Science 2012; 336: 1037-40.

71. Adams BD, Claffey KP, White BA. Argonaute-2 expression is regulated by epidermal growth factor receptor and mitogen-activated protein kinase signaling and correlates with a transformed phenotype in breast cancer cells. Endocrinology 2009; 150: 14-23.

72. Koesters R, Adams V, Betts D, Moos R, Schmid M, Siermann A, Hassam S, Weitz S, Lichter P, Heitz PU, von Knebel Doeberitz M, Briner J. Human eukaryotic initiation factor EIF2C1 gene: cDNA sequence, genomic organization, localization to chromosomal bands 1p34-p35, and expression. Genomics 1999; 61: 210-8.
73. Li L, Yu C, Gao H, Li Y. Argonaute proteins: potential biomarkers for human colon cancer. BMC Cancer 2010; 10: 38.

74. Parisi C, Giorgi C, Batassa EM, Braccini L, Maresca G, D'Agnano I, Caputo V, Salvatore A, Pietrolati F, Cogoni C, Catalanotto C. Ago1 and Ago2 differentially affect cell proliferation, motility and apoptosis when overexpressed in SH-SY5Y neuroblastoma cells. FEBS Lett 2011; 585: 2965-71.

75. Sasaki T, Shiohama A, Minoshima S, Shimizu N. Identification of eight members of the Argonaute family in the human genome small star, filled. Genomics 2003; 82: 323-30.

76. Valdmanis PN, Gu S, Schuermann N, Sethupathy P, Grimm D, Kay MA. Expression determinants of mammalian argonaute proteins in mediating gene silencing. Nucleic Acids Res 2012; 40: 3704-13.

77. Seto AG, Kingston RE, Lau NC. The coming of age for Piwi proteins. Mol Cell 2007; 26: 603-9.

78. Grimm D, Wang L, Lee JS, Schurmann N, Gu S, Borner K, Storm TA, Kay MA. Argonaute proteins are key determinants of RNAi efficacy, toxicity, and persistence in the adult mouse liver. J Clin Invest 2010; 120: 3106-19.

79. Fredrick K, Ibba M. How the sequence of a gene can tune its translation. Cell 2010; 141: 227-9.

80. Wang D, Zhang Z, O'Loughlin E, Lee T, Houel S, O'Carroll D, Tarakhovsky A, Ahn NG, Yi R. Quantitative functions of Argonaute proteins in mammalian development. Genes Dev 2012; 26: 693-704.

81. Hafner M, Landthaler M, Burger L, Khorshid M, Hausser J, Berninger P, Rothballer A, Ascano M Jr, Jungkamp AC, Munschauer M, Ulrich A, Wardle GS, Dewell S, Zavolan M, Tuschl T. Transcriptome-wide identification of RNA-binding protein and microRNA target sites by PAR-CLIP. Cell 2010; 141 : 129-41.

82. Landthaler M, Gaidatzis D, Rothballer A, Chen PY, Soll SJ, Dinic L, Ojo T, Hafner M, Zavolan M, Tuschl T. Molecular characterization of human Argonaute-containing ribonucleoprotein complexes and their bound target mRNAs. RNA 2008; 14 : 2580-96.

83. Broderick JA, Salomon WE, Ryder SP, Aronin N, Zamore PD. Argonaute protein identity and pairing geometry determine cooperativity in mammalian RNA silencing. RNA 2011; 17 : 1858-69.

84. Juvvuna PK, Khandelia P, Lee LM, Makeyev EV. Argonaute identity defines the length of mature mammalian microRNAs. Nucleic Acids Res 2012; 40: 6808-20.

85. Qi HH, Ongusaha PP, Myllyharju J, Cheng D, Pakkanen O, Shi Y, Lee SW, Peng J, Shi Y. Prolyl 4-hydroxylation regulates Argonaute 2 stability. Nature 2008; 455: 421-4.

86. Peters L, Meister G. Argonaute proteins: mediators of RNA silencing. Mol Cell 2007; 26: 611-23.

87. Zeng Y, Sankala H, Zhang X, Graves PR. Phosphorylation of Argonaute 2 at serine-387 facilitates its localization to processing bodies. Biochem J 2008; 413: 429-36.

88. Rudel S, Wang Y, Lenobel R, Korner R, Hsiao HH, Urlaub H, Patel D, Meister G. Phosphorylation of human Argonaute proteins affects small RNA binding. Nucleic Acids Res 2011; 39: 2330-43.

89. Leung AK, Young AG, Bhutkar A, Zheng GX, Bosson AD, Nielsen CB, Sharp PA. Genome-wide identification of Ago2 binding sites from mouse embryonic stem cells with and without mature microRNAs. Nat Struct Mol Biol 2011; 18 : 237-44.

90. Caiafa P, Zlatanova J. CCCTC-binding factor meets poly(ADPribose) polymerase-1. J Cell Physiol 2009; 219: 265-70. 
91. Rybak A, Fuchs H, Hadian K, Smirnova L, Wulczyn EA, Michel G, Nitsch R, Krappmann D, Wulczyn FG. The let-7 target gene mouse lin-41 is a stem cell specific E3 ubiquitin ligase for the miRNA pathway protein Ago2. Nat Cell Biol 2009; 11: 1411-20.

92. Chu Y, Yue X, Younger ST, Janowski BA, Corey DR. Involvement of argonaute proteins in gene silencing and activation by RNAs complementary to a non-coding transcript at the progesterone receptor promoter. Nucleic Acids Res 2010; 38 : 7736-48.

93. Janowski BA, Huffman KE, Schwartz JC, Ram R, Nordsell R, Shames DS, Minna JD, Corey DR. Involvement of AGO1 and AGO2 in mammalian transcriptional silencing. Nat Struct Mol Biol 2006; 13: 787-92.

94. Kim DH, Villeneuve LM, Morris KV, Rossi JJ. Argonaute-1 directs siRNA-mediated transcriptional gene silencing in human cells. Nat Struct Mol Biol 2006; 13: 793-7.

95. Li LC, Okino ST, Zhao H, Pookot D, Place RF, Urakami S, Enokida H, Dahiya R. Small dsRNAs induce transcriptional activation in human cells. Proc Natl Acad USA 2006; 103: 17337-42.

96. Morris KV, Santoso S, Turner AM, Pastori C, Hawkins PG. Bidirectional transcription directs both transcriptional gene activation and suppression in human cells. PLoS Genet 2008; 4 : e1000258.

97. Napoli S, Pastori C, Magistri M, Carbone GM, Catapano $\mathrm{CV}$. Promoter-specific transcriptional interference and c-myc gene silencing by siRNAs in human cells. EMBO J 2009; 28: 1708-19.

98. Suzuki K, Shijuuku T, Fukamachi T, Zaunders J, Guillemin G, Cooper D, Kelleher A. Prolonged transcriptional silencing and CpG methylation induced by siRNAs targeted to the HIV-1 promoter region. J RNAi Gene Silencing 2005; 1: 66-78.

99. Kim DH, Saetrom P, Snove O Jr, Rossi JJ. MicroRNA-directed transcriptional gene silencing in mammalian cells. Proc Natl Acad Sci USA 2008; 105: 16230-5.

100. Piriyapongsa J, Bootchai C, Ngamphiw C, Tongsima S. MicroPIR: an integrated database of microRNA target sites within human promoter sequences. PloS One 2012; 7: e33888.

101. Place RF, Li LC, Pookot D, Noonan EJ, Dahiya R. MicroRNA373 induces expression of genes with complementary promoter sequences. Proc Natl Acad Sci USA 2008; 105: 1608-13.

102. Tan Y, Zhang B, Wu T, Skogerbo G, Zhu X, Guo X, He S, Chen R. Transcriptional inhibiton of Hoxd4 expression by miRNA-10a in human breast cancer cells. BMC Mol Biol 2009; 10: 12 .

103. Younger ST, Corey DR. Transcriptional gene silencing in mammalian cells by miRNA mimics that target gene promoters. Nucleic Acids Res 2011; 39: 5682-91.

104. Zardo G, Ciolfi A, Vian L, Starnes LM, Billi M, Racanicchi S, Maresca C, Fazi F, Travaglini L, Noguera N, Mancini M, Nanni M, Cimino G, Lo-Coco F, Grignani F, Nervi C. Polycombs and microRNA-223 regulate human granulopoiesis by transcriptional control of target gene expression. Blood 2012; 119: 4034-46.

105. Moazed D. Mechanisms for the inheritance of chromatin states. Cell 2011; 146: 510-8.

106. Pushpavalli SN, Bag I, Pal-Bhadra M, Bhadra U. Drosophila Argonaute-1 is critical for transcriptional cosuppression and heterochromatin formation. Chromosome Res 2012; 20: 333-51.

107. Spivakov M, Fisher AG. Epigenetic signatures of stem-cell identity. Nat Rev Genet 2007; 8: 263-71.
108. Burroughs AM, Ando Y, de Hoon ML, Tomaru Y, Suzuki H, Hayashizaki Y, Daub CO. Deep-sequencing of human Argonaute-associated small RNAs provides insight into miRNA sorting and reveals argonaute association with RNA fragments of diverse origin. RNA Biol 2011; 8: 158-77.

109. Allo M, Buggiano V, Fededa JP, Petrillo E, Schor I, de la Mata M, Agirre E, Plass M, Eyras E, Elela SA, Klinck R, Chabot B, Kornblihtt AR. Control of alternative splicing through siRNAmediated transcriptional gene silencing. Nat Struct Mol Biol 2009; 16: 717-24.

110. Liu J, Hu J, Corey DR. Expanding the action of duplex RNAs into the nucleus: redirecting alternative splicing. Nucleic Acids Res 2012; 40: 1240-50.

111. Lee HC, Chang SS, Choudhary S, Aalto AP, Maiti M, Bamford DH, Liu Y. QiRNA is a new type of small interfering RNA induced by DNA damage. Nature 2009; 459: 274-7.

112. Fabian MR, Sonenberg N, Filipowicz W. Regulation of mRNA translation and stability by microRNAs. Annu Rev Biochem 2010; 79: 351-79.

113. Henke JI, Goergen D, Zheng J, Song Y, Schuttler CG, Fehr C, Junemann C, Niepmann M. MicroRNA-122 stimulates translation of hepatitis C virus RNA. EMBO J 2008; 27: 3300-10.

114. Orom UA, Nielsen FC, Lund AH. MicroRNA-10a binds the $5^{\prime}$ UTR of ribosomal protein mRNAs and enhances their translation. Mol Cell 2008; 30: 460-71.

115. Vasudevan S, Tong Y, Steitz JA. Switching from repression to activation: microRNAs can up-regulate translation. Science 2007; 318: 1931-4.

116. Olsen PH, Ambros V. The lin-4 regulatory RNA controls developmental timing in Caenorhabditis elegans by blocking lin-14 protein synthesis after the initiation of translation. Dev Biol 1999; 216: 671-80.

117. Seggerson K, Tang L, Moss EG. Two genetic circuits repress the Caenorhabditis elegans heterochronic gene lin-28 after translation initiation. Dev Biol 2002; 243: 215-25.

118. Kim J, Krichevsky A, Grad Y, Hayes GD, Kosik KS, Church GM, Ruvkun G. Identification of many microRNAs that copurify with polyribosomes in mammalian neurons. Proc Natl Acad Sci USA 2004; 101: 360-5.

119. Maroney PA, Yu Y, Fisher J, Nilsen TW. Evidence that microRNAs are associated with translating messenger RNAs in human cells. Nat Struct Mol Biol 2006; 13: 1102-7.

120. Nelson PT, Hatzigeorgiou AG, Mourelatos Z. MiRNP:mRNA association in polyribosomes in a human neuronal cell line. RNA 2004; 10: 387-94.

121. Nottrott S, Simard MJ, Richter JD. Human let-7a miRNA blocks protein production on actively translating polyribosomes. Nat Struct Mol Biol 2006; 13: 1108-14.

122. Petersen CP, Bordeleau ME, Pelletier J, Sharp PA. Short RNAs repress translation after initiation in mammalian cells. Mol Cell 2006; 21: 533-42.

123. Friend K, Campbell ZT, Cooke A, Kroll-Conner P, Wickens MP, Kimble J. A conserved PUF-Ago-eEF1A complex attenuates translation elongation. Nat Struct Mol Biol 2012; 19: 176-83.

124. Bhattacharyya SN, Habermacher R, Martine U, Closs EI, Filipowicz W. Relief of microRNA-mediated translational repression in human cells subjected to stress. Cell 2006; 125: 1111-24.

125. Ding XC, Grosshans H. Repression of C. elegans microRNA targets at the initiation level of translation requires GW182 proteins. EMBO J 2009; 28: 213-22. 
126. Huang J, Liang Z, Yang B, Tian H, Ma J, Zhang H. Derepression of microRNA-mediated protein translation inhibition by apolipoprotein B mRNA-editing enzyme catalytic polypeptide-like 3G (APOBEC3G) and its family members. J Biol Chem 2007; 282: 33632-40.

127. Pillai RS, Bhattacharyya SN, Artus CG, Zoller T, Cougot N, Basyuk E, Bertrand E, Filipowicz W. Inhibition of translational initiation by let-7 microRNA in human cells. Science 2005; 309: 1573-6.

128. Mathonnet G, Fabian MR, Svitkin YV, Parsyan A, Huck L, Murata T, Biffo S, Merrick WC, Darzynkiewicz E, Pillai RS, Filipowicz W, Duchaine TF, Sonenberg N. MicroRNA inhibition of translation initiation in vitro by targeting the cap-binding complex eIF4F. Science 2007; 317: 1764-7.

129. Humphreys DT, Westman BJ, Martin DI, Preiss T. MicroRNAs control translation initiation by inhibiting eukaryotic initiation factor 4E/cap and poly(A) tail function. Proc Natl Acad Sci USA 2005 ; 102: 16961-6.

130. Wakiyama M, Takimoto K, Ohara O, Yokoyama S. Let-7 microRNA-mediated mRNA deadenylation and translational repression in a mammalian cell-free system. Genes Dev 2007; 21: 1857-62.

131. Walters RW, Bradrick SS, Gromeier M. Poly(A)-binding protein modulates mRNA susceptibility to cap-dependent miRNAmediated repression. RNA 2010; 16: 239-50.

132. Eulalio A, Huntzinger E, Izaurralde E. GW182 interaction with Argonaute is essential for miRNA-mediated translational repression and mRNA decay. Nat Struct Mol Biol 2008; 15: 346-53.

133. Kinch LN, Grishin NV. The human Ago2 MC region does not contain an eIF4E-like mRNA cap binding motif. Biol Direct 2009; 4: 2 .

134. Frank F, Fabian MR, Stepinski J, Jemielity J, Darzynkiewicz E, Sonenberg N, Nagar B. Structural analysis of 5'-mRNA-cap interactions with the human AGO2 MID domain. EMBO Rep 2011; 12: 415-20.

135. Iwasaki S, Kawamata T, Tomari Y. Drosophila argonaute1 and argonaute2 employ distinct mechanisms for translational repression. Mol Cell 2009; 34: 58-67.

136. Fabian MR, Mathonnet G, Sundermeier T, Mathys H, Zipprich JT, Svitkin YV, Rivas F, Jinek M, Wohlschlegel J, Doudna JA, Chen CY, Shyu AB, Yates JR III, Hannon GJ, Filipowicz W, Duchaine TF, Sonenberg N. Mammalian miRNA RISC recruits CAF1 and PABP to affect PABP-dependent deadenylation. Mol Cell 2009; 35: 868-80.

137. Wightman B, Ha I, Ruvkun G. Posttranscriptional regulation of the heterochronic gene lin-14 by lin- 4 mediates temporal pattern formation in C. elegans. Cell 1993; 75: 855-62.

138. Baek D, Villen J, Shin C, Camargo FD, Gygi SP, Bartel DP. The impact of microRNAs on protein output. Nature 2008; 455 : 64-71.

139. Selbach M, Schwanhausser B, Thierfelder N, Fang Z, Khanin R, Rajewsky N. Widespread changes in protein synthesis induced by microRNAs. Nature 2008; 455: 58-63.

140. Hendrickson DG, Hogan DJ, McCullough HL, Myers JW, Herschlag D, Ferrell JE, Brown PO. Concordant regulation of translation and mRNA abundance for hundreds of targets of a human microRNA. PLoS Biol 2009; 7: e1000238.

141. Guo H, Ingolia NT, Weissman JS, Bartel DP. Mammalian microRNAs predominantly act to decrease target mRNA levels. Nature 2010; 466: 835-40.
142. Eulalio A, Huntzinger E, Nishihara T, Rehwinkel J, Fauser M, Izaurralde E. Deadenylation is a widespread effect of miRNA regulation. RNA 2009; 15: 21-32.

143. Bazzini AA, Lee MT, Giraldez AJ. Ribosome profiling shows that miR-430 reduces translation before causing mRNA decay in zebrafish. Science 2012; 336: 233-7.

144. Djuranovic S, Nahvi A, Green R. MiRNA-mediated gene silencing by translational repression followed by mRNA deadenylation and decay. Science 2012; 336: 237-40.

145. Eulalio A, Tritschler F, Izaurralde E. The GW182 protein family in animal cells: new insights into domains required for miRNAmediated gene silencing. RNA 2009; 15: 1433-42.

146. Behm-Ansmant I, Rehwinkel J, Doerks T, Stark A, Bork P, Izaurralde E. MRNA degradation by miRNAs and GW182 requires both CCR4:NOT deadenylase and DCP1:DCP2 decapping complexes. Genes Dev 2006; 20: 1885-98.

147. Till S, Lejeune E, Thermann R, Bortfeld M, Hothorn M, Enderle D, Heinrich C, Hentze MW, Ladurner AG. A conserved motif in Argonaute-interacting proteins mediates functional interactions through the Argonaute PIWI domain. Nat Struct Mol Biol 2007; 14: 897-903.

148. Takimoto K, Wakiyama M, Yokoyama S. Mammalian GW182 contains multiple Argonaute-binding sites and functions in microRNA-mediated translational repression. RNA 2009; 15: 1078-89.

149. Lazzaretti D, Tournier I, Izaurralde E. The C-terminal domains of human TNRC6A, TNRC6B, and TNRC6C silence bound transcripts independently of Argonaute proteins. RNA 2009; 15: 1059-66.

150. Zipprich JT, Bhattacharyya S, Mathys H, Filipowicz W. Importance of the C-terminal domain of the human GW182 protein TNRC6C for translational repression. RNA 2009; 15: 781-93.

151. Huntzinger E, Braun JE, Heimstadt S, Zekri L, Izaurralde E. Two PABPC1-binding sites in GW182 proteins promote miRNA-mediated gene silencing. EMBO J 2010; 29: 4146-60.

152. Zekri L, Huntzinger E, Heimstadt S, Izaurralde E. The silencing domain of GW182 interacts with PABPC1 to promote translational repression and degradation of microRNA targets and is required for target release. Mol Cell Biol 2009; 29: 6220-31.

153. Braun JE, Huntzinger E, Fauser M, Izaurralde E. GW182 proteins directly recruit cytoplasmic deadenylase complexes to miRNA targets. Mol Cell 2011; 44: 120-33.

154. Chekulaeva M, Mathys H, Zipprich JT, Attig J, Colic M, Parker R, Filipowicz W. MiRNA repression involves GW182-mediated recruitment of CCR4-NOT through conserved W-containing motifs. Nat Struct Mol Biol 2011; 18: 1218-26.

155. Fabian MR, Cieplak MK, Frank F, Morita M, Green J, Srikumar T, Nagar B, Yamamoto T, Raught B, Duchaine TF, Sonenberg N. MiRNA-mediated deadenylation is orchestrated by GW182 through two conserved motifs that interact with CCR4-NOT. Nat Struct Mol Biol 2011; 18: 1211-7.

156. Cooke A, Prigge A, Wickens M. Translational repression by deadenylases. J Biol Chem 2010; 285: 28506-13.

157. Hafner M, Ascano M Jr., Tuschl T. New insights in the mechanism of microRNA-mediated target repression. Nat Struct Mol Biol 2011; 18: 1181-2.

Received June 5, 2012; accepted July 20, 2012 


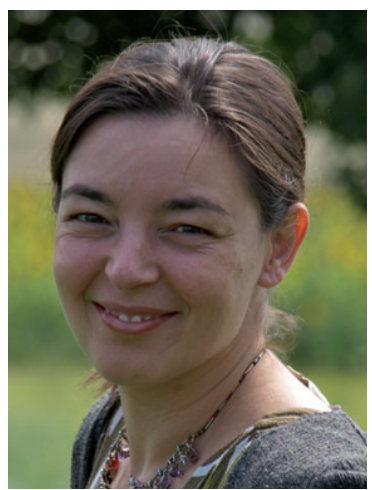

Corinna Giorgi obtained her $\mathrm{PhD}$ in Genetics and Molecular Biology in 2002 at the University of Rome "La Sapienza", working in the laboratory of Prof. Irene Bozzoni. She then joined Prof. Melissa Laboratory as a Howard Hughes postdoctoral fellow in the Biochemistry Department of Brandeis University (MA) in the USA. Since 2007, she joined EBRI, the European Brain Research Institute in Rome, initially in Prof. Carlo Cogoni's laboratory, and currently as a project leader. In 2009 she was awarded a Marie Curie International Reintegration Grant. The overarching focus of her research is to understand how post-transcriptional regulation of gene expression, particularly at the level of mRNA metabolism, participates in modulating neuronal functions.

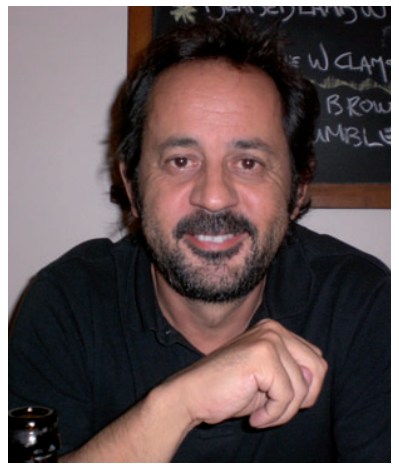

Carlo Cogoni studied Biology at the University of Rome, Italy. He was appointed Assistant Professor and Group Leader at the European Brain Research Institute in Rome. $\mathrm{He}$ is currently Associate Professor at the Dept. of Biotechnology and Haematology, Sapienza University of Rome. He pioneered the studies on the dissection of the silencing machinery by using the fungus Neurospora crassa as a model system. More recently, his research interests focus on the role of the RNA-mediated gene silencing machinery in neuronal cells.

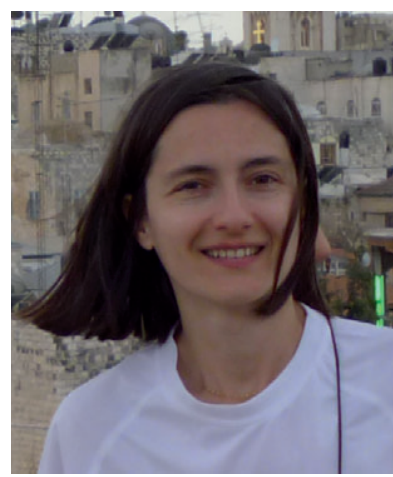

Caterina Catalanotto received her $\mathrm{PhD}$ in "Human Biology: Cellular and Molecular Bases" from the University of Rome "Sapienza" in 2003. She became assistant professor at the University of Rome "Sapienza" in the Department of Cellular Biotechnology and Haematology in 2008. Her research program is focused on microRNAs and Argonaute proteins. 